\title{
BURGUESIA NACIONAL, DESARROLLO Y DEPENDENCIA: EL CASO DE MÉXICO
}

\author{
Ricardo Cinta \\ (El Colegio de México)
}

El «análisis de la dependencia» y el concepto de "país dependiente» penetran toda la producción científico-social latinoamericana de la última década. La noción de dependencia se va decantando dialécticamente tanto como crítica de las teorías del desarrollo y de la modernización norteame. ricanas de los sesenta, cuanto, alternativamente, como una concepción integrada del desarrollo en la que economía, sociedad y política se articulan para entender el desenvolvimiento del sistema capitalista en las naciones de la periferia internacional. Dado que la América Latina no está reproduciendo tardíamente el decurso histótico de los países centrales, ni ha recorrido mecánicamente los «estadios del desarrollo» del futurible rostowiano, era necesaria una respuesta crítica, genuina y especifica. El presente ensayo, tomando como case study el desarrollo mexicano desde la postguerra, trata de contribuir a esa tarea. Al mismo tiempo, ofrece una versión concreta renovada de la dependencia, en la que - - lejos de nominalismos y demagogias - los procesos de desarrollo capitalista y de dependencia no aparecen como antagónicos o permanentemente contradictorios. Antes al contrario, el desarrollo capitalista mexicano prueba que existe un tipo específico de dependencia que da viabilidad singular a la industrjali. zación de la periferia. 


\section{Introducción}

En los últimos años, la literatura sobre el desarrollo de América La* tina se ha visto crecientemente permeada por el uso de la noción de «país dependiente». Como concepción global, esta noción ha venido a ejercer una doble función: Ia de la crítica a las teorías convencionales del desarrollo y, a partir de ella, la recuperación, en el plano analítico, de la intersección entre economía, sociedad y política, capaz de sustentar una interpretación integrada, estructural e históricamente referida a los procesos de formación del sistema capitalista en los países y regiones de la periferia internacional. No es preciso, entretanto, insistir en ninguno de los dos siguientes aspectos: ni en el alcance de su intención crítica, ni, por derivación, en el alcance relativo de su capacidad explicativa.

Por lo que se refere al primer punto, las argumentaciones críticas son suficientemente conocidas y las evidencias en que se apoyan razonablemente signiffcativas para poner en duda lo que se tenía como establecido en las concepciones lineal-evolucionistas, anhistóticas, de la transición hacia el «crecimiento autosostenido» (el Take-off) y el arribo a la «modernizaciónn. En efecto, la América Latina no está reproduciendo, tardíamente,

1. Es obvio que a cada enfoque corresponde una varianza interna que debe tenetse en cuenta. No obstante, es perfectamente posible identificarlos como aiteznativos. Existen muchas obras representativas de cada uno de ellos y de sus antecedentes. Ilustrativamente, deben citarse, para el primero de ellos: W. W. Rostow, Las etapas del crecimiento econbmico. Un manifiesto no comunista (México: Fondo de Cultura Económica, 1962); Gino Germani, Política y sociedad en una époce de transición (Buenos Aires: Paiđós, 1966); John J. Jhonson, La transformación politica de América Latina, El surgimiento de los sectores medios (Buenos Aires: Solat/Hachette, 1962). Institucionalmente, muchos de los más divuigados trabajos de la CEPAL, principalmente los elaborados en los años 50, son un buen ejemplo de este tipo de análisis. Podría decirse, como historia intelectual, que los escritos de Raúl Prebisch, Singer, Myrdal y Medina Echavarría, entre otros, constituyen un antecedente crítico, 
la bistoria social de los países avanzados, ni la formación de éstos puede ser considerada como pauta idealizada y universal del desarrollo capitalista de los países que «se quedaron atrás».

En relación con el segundo aspecto, sobre los alcances y limitaciones de los análisis basados en la perspectiva de los estudios sobre la dependencia, un balance razonable excede el propósito limitado de este trabajo. Por lo demás, esta tarea ya ha sido tealizada. ${ }^{2}$ Sin embargo, dada la heterogeneidad conceptual y metodológica que los caracteriza - pese a que provengan de un campo teórico común- conviene precisar, brevemente, algunos problemas relacionados con su conceptualización evitando, con ello, posibles fuentes de confusión que entorpezcan la comprensión del análisis concreto que me propongo.

En este intento de clarificación dejo de lado, deliberadamente, toda discusión relativa al significado semántico del término dependencia y, en particular, a dos de sus derivaciones que sin poseer significado teórico preciso alguno han llegado a ser utilizadas como parte de la crítica formal al empleo del concepto de dependencia: la postulación de relaciones de «interdependencia», ${ }^{3}$ por un lado, y, por otro, la reificación de la «inde-

aunque parcial, de ese primer enfoque; sobre todo, en cuanto a la discusión de la teoría clásica del comercio internacional tealizada por los primeros, en el campo económico, y la reconsideración del papel de los «agentes sociales» del desarrollo -principalmente las clases medias y las élites- elaborada por el últirno. Para el segundo enfoque, consúltese: F. H. Cardoso y E. Faletto, Dependencia y desarrollo en América Latina (México: Siglo XXI Editores, 1969); F. H. Cardoso, Cuestiones de sociologia del desarrollo en América Latina (Santiago de Chile: Editorial Universitatia, 1969); Osvaldo Sunkel, El marco bistórico del proceso de desarrollo y subdesarrollo (Santiago de Chile: ILPES, 1967); Theoionio Dos Santos, «El nuevo carácter de Ia dependencia», en $T$. Dos Santos, et al, La crisis del desarrollismo y la nueva dependencia (Lima: Instituto de Estudios Peruanos, 1969); Rodolfo Stavenhagen, «Siete tesis equivocadas sobre América Latina», en R. Stavenhagen, Sociología y subdesarrollo (México: Editorial Nuestro Tiempo, 1971).

2. F. H. Cardoso, "¿"Teoría de la dependencia" o análisis de situaciones concretas de dependencia?», en Revista Latinoamericana de Ciencia Politica, vol. 1, núm. 3 (1970); F. H. Cardoso, «otas sobre el estado actual de los estudios de la dependencian, en Sergio Bagú, et al., Problemas del subdesarrollo latinoamericano (México: Editorial Nuestro Tiempo, 1973); F. H. Cardoso, «Contradicciones del desarrollo asociado», en Desarrollo economico (1970). Otro escrito importante es el de Francisco Weffort, «Notas sobre la "Teoría de la dependencia": ¿Teoría de clase o ideología Nacional?», en Revista Latinoamericana de Ciencia Politica, vol. I, núm. 3 (1970).

3. Raymond Vernon, Multi-National Enterprises: Their Relation to Dependency and Interdependence (Harvard University: Center for International Affairs, 1973), mimeo, y Robert Packenham, Latin American Dependency Theories: Strengths and Weaknesses (1974). Mimeo. 
pendencia» como supuesto concepto recíproco o «contra-situación». En el primer caso, se omiten las posiciones y funciones diferenciales con que las partes intervienen en la «interdependencia» y las situaciones de dominación-subordinación en ellas inscritas, condenando el análisis a un simple procedimiento analógico formal. En el segundo, el análisis de la dependencia acaba por ser confundido con el establecimiento de una ideología nacional, y queda reducido a los estrechos límites de una tautología.

Desde el punto de vista sustantivo, los problemas en el análisis de la dependencia son, por supuesto, de índole diferente. Ellos se definen en el marco de una estrategia teórico-metodológica encaminada hacia una interpretación integrada del desarrollo, de corte bistórico-estructural, y elaborada a partir del análisis de situaciones concretas. ¿Qué significa esto?

En primer lugar, que la interpretacion de las situaciones de subdesarrollo no se deducen a partir de algún «modelo» posible de ordenación y agregación de variables -económicas, sociales y políticas- destinado a la construcción de sistemas clasificatorios. No, metodológicamente, la categoría de dependencia no se inspira en una intención nominalista. ${ }^{4}$ En vez de ello, pretende asignar al subdesarrollo un significado historico particular, concibiéndolo como parte del proceso de formación del sistema productivo mundial; es decir, como resultado de la vinculación de las economías periféricas al metcado mundial, primero bajo su condición de «colonias», luego como sociedades nacionales.

La situación de subdesarrojlo se produjo históricamente cuando la expansión del capitalismo comercial y luego del capitalismo industrial vinculó a un mismo mercado economías que, además de presentar grados diversos de difetenciación del sistema productivo, pasaron a ocupar posiciones distintas en la estructura global del sistema capitalista. De ahí que entre las economf́as desarrolladas y las subdesarrolladas no sólo exista una diferencia de etapa o estado del sistema productivo, sino también de función o posición dentro de una misma estructura económica internacional de producción y distribucion. Ello supone, por otro lado, una estructura definida de relaciones de dominación. ${ }^{5}$

4. Para la distinción metodológica entre conceptos «reales» y «nominales» en las ciencias sociales, véase $R$. Biersted, «Nominal and Real Definitions in Sociological Theory", en Lilewellyn Gross (ed.), Symposium on Sociological Tbeory (Nueva York: Horper, 1959).

5. F. H. Cardoso y E. Faletto, Dependencia..., op. cit., p. 23. 
En segundo lugat, vistas en su determinación histórica, y atendiendo a su posición y función internacionales, las economías y sociedades subdesartolladas podrían ser conceptualizadas, por un simple trasplante, como «periféricas», por contraposición a las economías y sociedades «centrales» del mismo sistema. De hecho, este reemplazo ha sido llevado a cabo en un buen número de trabajos cuya potencialidad analítica quedó disminuida ante el atractivo que, como categoría de denuncia, vino a ejercer el binomio centro periferia sobre muchos autores de la izquierda intelectual.

Tal teemplazo, sin embargo, es esencialmente equivocado por cuanto la relación centro-periferia, o desarrollo-subdesarrollo, empleadas en exclusiva, sólo pueden conducir a un análisis parcial, de posición y función en el primer caso, de estado o situación en el segundo. Esto fue muy clata. mente indicado por Cardoso y Faletto, al precisar que los conceptos de desarrollo y subdesarrolio no pueden ser sustituidos por los de centro y periferia ni, como si fuesen una síntesis de ambos, por los de economías autónomas y economías dependientes:

De hecho, son distintas tanto las dimensiones a que estos conceptos se refieren como su significación teórica. La noción de dependencia alude directamente a las condiciones de existencia y funcionamiento del sisterna económico y del sistema político, mostrando las vinculaciones entre ambos, tanto en lo que se refiere al plano interno de los países como al externo. La noción de subdesarrollo caracteriza a un estado o grado de diferenciación del sistema productivo... sir acentuar las pautas de control de las decisiones de producción y consumo, ya sea internamente (socialismo, capitalismo, etc.), o externamente (colonialismo, periferia del mercado mundial, etc.). Las nociones de «centro» y "periferia» por su parte, subrayan las funciones que cumplen Ias economías subdesarrolladas en el mercado mundial, sin destacar para nada los factores político-sociales implicados en la situación de dependencia. ${ }^{6}$

A partir de este tipo de conceptualización, una interpretación integrada del desarrollo no podría suponer, tampoco, la existencia de un nexo inmediato entre la diferenciación del sistema económico, el establecimiento de centros autónomos de decisión y la traslación de la periferia al centro. Las transformaciones del sistema productivo no se traducen necesariamente

6. Ibid..., pp. 24.25 . 
en un robustecimiento de la "autonomía nacional» de decisiones y de los mecanismos sociales que las condicionan, así como, por otra parte, la relativa autonomía de una «sociedad nacional» no tiene como concomitante, a fortiori, una expansión del apparato productivo y formas de distribución de la renta equiparables a los países centrales desarrollados 0 , incluso, a países periféticos «en desartoll $\gg$ ».

Lo que el concepto de dependencia pretende, precisamente, es otorgar significado a la manera como estos hechos se combinan, en momentos dados, estableciendo -por su :ntermedio- las relaciones que hacen inteligibles las situaciones empiričs en función del modo de conexión entre los componentes estructurales internos y externos. Ttátase pues, de comprender la dinámica estructural y las determinaciones históricas que ponen en movimiento el desartollo de las sociedades de la periferia internacional, en la dialéctica de sus mediaciones políticas y sociales tal y como se reproducen interna y externamente.

Asumiendo esta perspectiva, el presente trabajo adquiere una doble delimitación. Históricamente, se halla circunscrito a los cambios ocurridos a partir de la posguerta y qus establecen, como se intenta mostrar, un nuevo tipo específico de depentencia que da viabilidad a la industrializa. ción de la periferia. En este propósito, no se endosan, por tanto, aquellas formulaciones sobre la dependencia que insisten, sin fundamento, en una contradicción permanente y scibredeterminada entre dependencia y des* artollo.

\section{Industrializacion nacional $y$ desendencia}

Las condiciones internacionales que emergieron y se mantuvieron presentes en el mundo capitalista entre 1929 y el segundo conflicto bélico mundial se tradujeron, para la mayor parte de la América Latina, en una importante posibilidad coyunttral de iniciar, sobre bases relativamente firmes, una nueva etapa en su oroceso de desarrollo, que a través del impulso a la industrialización nacional iniplicata también un robustecimiento de su autonomía sobre el proceso global de desarrollo y la redefinición de las viejas estructuras de dominación interna en favor de los grupos y clases sociales que emergían vinculad is a la economía urbano-industrial.

7. El caso más representativo ide esta tendencia es posiblemente el de los trabajos de André Gunder Frank. Véasi: su Desarrollo del subdesarrollo (México: Escuela Nacionai de Antropología e Histori, 1970) y su Lumpenburguesía: Lumpenproletoriado (México: Editorial ERA, 1971: 
La crisis mundial y sus efectos sobre la paralización relativa de los movimientos internacionales de capital, se expresaton en un sensible descenso de las inversiones extranjeras y, por tanto, en la pérdida del dinamismo de los enclaves mineros y agrícolas orientados a la exportación que durante el largo período que los economistas han denominado de «crecimiento hacia afueras, constituyeron el centro de la actividad economica aun cuando algunos países de la región, como México, Argentina, Btasil, Chile, Uruguay y Colombia principalmente, hubieran experimentado un inicio de industrialización, en parte como complementaria de la actividad exportadora y en parte dirigida a una cierta demanda interna de bienes de consumo representada por mercados locales o regionales con sede en los centros urbanos de la época.

Por otra parte, la sociedad mexicana, después de quince años de guerra civil, había conseguido debilitar y posteriormente romper las bases de dominio de la oligarquía terrateniente, tanto en lo económico como en lo político, al paso que se iniciaba una era de acentuamiento de su soberanía que se expresaba, entre otras formas, por la valorización del control nacional de sus recursos naturales. Tal fue el caso del petróleo, por ejemplo, que culminó con la expropiación de las compañías extranjeras en 1938 así como, por su parte, la nacionalización de los ferrocartiles y la reforma agraria.

En términos generales, el período se caracterizó por una fuerte disminución de la inversión extranjera, una intensificación de la inversión interna y una creciente participación estatal, fuertemente apoyada en los sectores populares e incluso en la naciente burguesía nacional -cuyos orígenes se remontan a los últimos años del porfiriato- que encontraba posibilidades cada vez más amplias de consolidación en el marco de una ideologia nacionalista del desarrollo que, en las condiciones provocadas por la gran depresión y la segunda guerra mundial, era fuertemente impulsada por el Estado a través del proceso de sustitución de importaciones como una política explícita de la estrategia de desarrollo «hacia adentro» y una política proteccionista que colocaba a disposición del sector empresarial una demanda ya creada y antes satisfecha a través de las importaciones.

Las afirmaciones formuladas encuentran suficiente apoyo en los datos que al respecto existen disponibles. Así, de 3.462 millones de dólares a que ascendian las inversiones norteamericanas en América Latina en 1929, según la CEPAL, descendieron a 2.803 millones en 1936 y a 2.696 millones en 1940. En México, las inversiones directas de los Estados Unidos, que experimentaron un gran crecimiento durante la última década del siglo xIx, ascendieton, de acuerdo con el Departamento de Comercio de los 
Estados Unidos, a 683 millones de dólates en 1929 habiendo descendido hacia fnes de 1940 a la cantidid de 358 miliones (Tabla 1).

\section{TABLA 1}

Inversiones notteameticanas en América Latina

y México

(Millınes de dólares)

\begin{tabular}{|c|c|c|c|}
\hline & 1929 & 1936 & 1940 \\
\hline $\begin{array}{l}\text { América Latina } \ldots \ldots \ldots \ldots \ldots \\
\text { México } \ldots \ldots \ldots \ldots \ldots \ldots \ldots \ldots . . . . . . . .\end{array}$ & $\begin{array}{r}3.462 \\
683\end{array}$ & $\stackrel{2.803}{-}$ & $\begin{array}{r}2.696 \\
358\end{array}$ \\
\hline
\end{tabular}

En sentido opuesto, el coruportamiento de la inversión interna tegis. tró un ascenso constante en el que no deben subestimarse los importantes efectos de la inversión pública destinada a las obras de infraestructura y a los servicios públicos en la unión y creación de mercados y en las facilidades para la formación de mar ufacturas básicas y complejos industriales. $\mathrm{La}$ invetsión pública, en pesos I corrientes, se ha incrementado de $82 \mathrm{mi}$ llones en 1925 a 137 millones en 1935 y a 290 en 1940 , habiendo alcanzado la cifra de 2.672 millones en 1950 que representaba el $44,2 \%$ de la inversión total del país, si sien ha venido perdiendo importancia, en términos relativos, con respectc a la inversión privada que para 1966 tepresentó, con 14.929,3 millones el $69,9 \%$ de la total. 9

Durante la posguerra - hasta 1950_, la inversión realizada en México llego a ocupar un lugar bastantio destacado si se le compara con países de ingreso per cápita similar (Tablir 2) y en la que después de los transportes y las comunicaciones, que ocujaron el primer lugar de la inversión en-

8. David Ibarra, «Mercados, dısarrollo y política económica: Perspectivas de la economía de México», en El peyfil de México en 1980 (México: Siglo XXI, 1970), vol. 1, p. 113.

9. Ibid..., pp. 115-116. 
tre 1939 y 1950 ( $28 \%$ de la inversión bruta interna), el segundo lo ocupó la industria con una participación del $23 \% .^{10}$

\section{TABLA 2}

Proporción media anual de la inversión total respecto al producto nacional bruto, por países y niveles de ingreso per cápita $1947-1950$

Ingreso

Per Cápita

PAISES *

Respecto a México

Guatemala Turquia Brasil Colombia Cuba Cbile

Menor $\quad 10,2 \quad 13,0$

Ligeramente

mayor

15,0

15,8

Mucho mayor

* Méxiço: 14,0.

En resumen, la etapa de desarrollo nacional que se verificó en México y América Latina -aunque con muy diversos logros si se observa por países- a través de la industrialización sustitutiva y de la consolidación del mercado interno, se rigió en función de la acumulación interna y estuvo claramente caracterizada por políticas proteccionistas.

Por otra parte, durante el proceso se había logrado formar, no sólo el mínimo de infraestructura e industrias de base para facilitar la continuidad del crecimiento, sino también un sector empresarial privado y mejor organizado para asumir, junto con el Estado, la conducción del desartollo.

10. Raúl Ortiz Mena, Víctor L. Utquidi, et al., «México, desarrollo económico y capacidad para absorber capital del exteriorn, en Problemas agrícolas e industriales de México, vol. IV, núm. 3 (1952), p. 21. Véase también James W. Wilkie, Tbe Mexican Revolution: Federal Expenditure and Social Change Since 1910 (University of California Press, 1970) y Clark W. Reynolds, La economia mexicana. Su estructura y cre. cimiento en el siglo XX. (México: Fondo de Cultura Económica, 1973). 
Es precisamente dentro de este tipo de situación estructural en el que fue posible la emergencia de in "proyecto nacional de desartollo autónomo" que, aunque no sin fricciones, enfatizaba la necesidad de impulsar el proceso de industrialización dentro del marco de cna política de desartollo que suponía un creciente control nacional de los centros de decisión a través del Estado y los sectotes privados nacionales y en alianza - o compromiso- con los grupos urbanos emergentes: clases medias y sectores populares, sobre todo de la clase obrera.

Esquemáticamente, el cualtro económico-político en el que esa ideología descansaba consistía en asignar objetivos e intereses comunes a la acción de los "actores sociales: en nombre de la Nación y en defensa de la Revolución. Liquidado el orden tradicional de dominación, conno ocurió en México, la presencia urganizada de las masas utbanas y rurales significaba la existencia de un movimiento nacional popular que, a la vez que garantizaba la solidez del nuevo orden -bajo la alianza multiclasista--, coincidiría con los objetivos de la política económica dictada ahora por los sectores productivos industriales orientados hacia el metcado interno.

Esta alianza nacional-desarrollista, vivida por algunos de los países latinoamericanos más industrializados -el vargtismo en Brasil y el pero nismo en Argentina-, adquirió en México características peculiares que contribuyeron no sólo a susten:arła sobre bases más sólidas, sino a la vez a otorgar a las clases dirigente; una mayor posibilidad de ejercer su liderazgo a largo plazo en condicior es de estabilidad, aun cuando la legitimidad de dicho liderazgo se haya ido desvaneciendo.

En primer tétmino, las condiciones estructurales internas a partir de las cuales se establecen las bases de consolidación de la burguesía industrial mexicana to implicaron, como en el caso de otros países, la necesidad de «negociar» con un sector tadicional agroexportador poderoso - como el cafetalero del Brasil-, deb.litado por la contracción del comercio internacional de 1929 , pero suficientemente fuerte y flexible " como para participar de la nueva situación e incluso beneficiarse de ella. ${ }^{12}$ En el caso mexicano se produjo una nueva tstructura de dominación, con la burguesía por delante, cuyas bases sociales dieron un nuevo contenido al Estado. En segundo lugar, el comienzc. de la institucionalización del proceso político emanado de la tevolución precede y coincide históricamente, con el

11. Sobre la Alexibilidad de las estructuras y élites tradicionales en Amética Latina, véase José Medina Echavarría, Consideraciones sociológicas sobre el desarrollo económico de América Latina (Bueros Aires: Solar/Hachette, 1964).

12. Consúltese, al respecto, F. H. Cardoso, Empresário industrial e desenvolvimento econômico no Brasil (São Paìlo: Difusāo Européia do Livro, 1964). 
obregonismo y el callismo, a la industrialización sustitutiva, momento dentro del cual se perfecciona el aparato político del Estado y se establecen las bases para la incorporación formal del movimiento obrero y campesino al recientemente constituido Partido Nacional Revolucionario (PNR), definiendo con ello las posibilidades institucionales de su participación a la vez que sentando las bases de su subordinación ideológica y política; institucionalización ésta que no fue dable en ningún otto país latinoamericano. ${ }^{13}$

Políticamente, esta época de acusado nacionalismo y desartollismo, que en ambos sentidos estuvo presente en la vida nacional hasta prácticamente la Segunda Guerra Mundial, adquirió tealidad doctrinaria en las tesis que fundamentaban la alianza multiclasista bajo la forma de la «unidad nacional frente al imperialismo», expresión que fue mantenida hasta mucho tiempo después, contribuyendo a desviar el enfrentamiento ideológico y político entre los grupos y clases sociales dentro del ptopio país.

Sin embargo, la evolución de la situación internacional se fue modificando, sobre todo una vez concluida la guerra, a la par que los países de América Latina que más habían avanzado en su industrialización mediante la sustitución fácil de importaciones, hacían frente a nuevos problemas y requerimientos más dif́́ciles de vencer para la consolidación de sus sistemas industriales.

La necesidad de asegutar la continuidad de la industrialización implicaba la creación de un nuevo sector industrial destinado a la producción de bienes intermedios y de capital, requetimiento para cuya satisfacción era preciso disponer de grandes sumas de capital y una tecnología considerablemente más avanzada si se le compara con la que se emplea en la fabricación de bienes de consumo en la industria ligera.

La manera como se hizo frente a esta situación implicó una teorientación sustancial de la política de desarroilo que se había ido gestando. Bajo nuevas condiciones, las élites empresariales latinoamericanas y los

13. Además, la incorporación de los sectores populares al aparato político de Estado no supuso la organización de los trabajadores como clase, sino que, por el contrario, auspició su escisión al organizar separadamente al sector campesino del obrero y a éstos del Ilamado «sector popular», en las tres grandes centrales en que hoy descansa la organización y funcionamiento del PRI: CNC, CTM y CNOP. Véanse al respecto las consideraciones de Vicente Lombardo Toledano en James W. Wilkie y Edra Monzón de Witkie, México visto en el siglo XX. Entrevistas de bistoria oral (México: Instituto Mexicano de Investigaciones económicas, 1969), p. 319 y ss. T'anbién Ricardo Cinta, Estado y sociedad en el capitolismo periférico: el caso de México (Yale University, 1974). Mimeo. 
Estados que integran la región, habrían de decidir los nuevos conteniz̉os socioeconómicos de la estrategia de desarrollo y definir los términos de sus relaciones con el exterior, dentro de los parámetros establecidos por las nuevas condiciones estructurale: que se empezaron a manifestar a partir de la posguerra.

La hipótesis que se sostiene en este trabajo, es que la explicación de Ia situación específica de dependencia que caracteriza el actual modelo de desarrollo mexicano, así como las condiciones estructurales internas y externas que lo han hecho posible, debe ser elaborada en función del nuevo tipo de vinculación que se estableció, desde la posguerra, con el sistema capitalista internacional y, en particular, con la economía norteanericana.

Prácticamente, México fue el único país latinoamericano que, concluidos los efectos favorables interiacionales de coyuntura a la industrialización de la región, pudo manterer una tasa elevada y sostenida de crecimiento. ${ }^{14}$ En ello han contado, desde luego, ciertos aspectos de su estructura económica -además de las particularidades histórico-políticas ya mencionadas-, como la relativa diversificación de su sector exportador y el papel que representa el turismo, así como el efecto que la desigualdad en la distribución del ingreso — mantenida durante tanto tiempo, pese al aumento de la productividad-, ha ejercido en favor de la acumulación de capital.

Después de 1945, el país mantuvo el conjunto de políticas proteccionistas que había puesto en fráctica desde la crisis del 29 destinadas a la protección del mercado inter:10, a impulsar la industrialización nacional y a elevar la autonomía interra. Sin embargo, las barteras aduaneras y arancelarias destinadas a limitat el ingreso de manufacturas desde los centros industriales no significaron el cierre del mercado interno al capital extemo. Por el contrario, fue precisamente dentro de esas condiciones que los proveedores de manufacturas pasaron a tealizar inversiones en el interior de las economías periféricas, aprovechando las condiciones de mercado creadas en la situación anterio: sobre todo en aquellos países que más habían logrado avanzar en su industrialización. Así, las inversiones nortearnericanas que en el año 1940 babían sido de 2.696 millones de dólares en América Latina, aumen aron a 2.721 millones en 1943, a 4.445 en 1950 y a 8.200 millones de dólares en 1961.

Por otra parte, las nuevas inversiones adquirieron una modalidad di-

14. Para comparaciones con Frasia y Argentina, F. H. Cardoso y E. Faletto, Dependencia..., op. cit., pp. 3-10, y F. H. Cardoso, Ideologias de la burguesía indussrial en sociedades dependientes (México: Siglo XXI, 1971). 
ferente. A diferencia del patrón que las caracterizó durante el llamado período de «crecimiento hacia afuera», las nuevas inversiones se han dirigido predominantemente al sector manufacturero. De acuerdo con los datos publicados por la Organización de Estados Americanos (OEA), ${ }^{15}$ las inversiones directas norteamericanas en cuatro de los países más industrializados del área se concentraron, en 1964, claramente en el sector de manufacturas: en Brasil, el 67,7\%; en México, el 58,7\%; en Argentina, el 56,3\% y en Uruguay el $40,0 \%$. Además, destaca también el hecho de que los principales países receptores son a su vez los más industrializados de América Latina (Tabla 3).

\section{TABLA 3}

Destino de la inversión norteamericana por países en 1964 (Millones de dólares)

\begin{tabular}{|c|c|}
\hline Pais & Monto total de las inversiones \\
\hline Venezuela................ & 2.808 \\
\hline 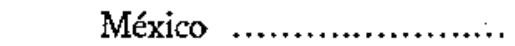 & 1.035 \\
\hline Brasil $\ldots \ldots \ldots \ldots, \ldots \ldots \ldots \ldots$ & 994 \\
\hline Argentina,$\ldots \ldots \ldots \ldots \ldots \ldots$ & 883 \\
\hline Chile $\ldots \ldots \ldots \ldots \ldots \ldots \ldots \ldots \ldots$. & 788 \\
\hline Panamá $\ldots . . . . . . . \ldots \ldots \ldots \ldots$ & 664 \\
\hline 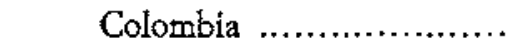 & 520 \\
\hline Perú $\ldots \ldots \ldots \ldots \ldots \ldots \ldots \ldots$ & 461 \\
\hline
\end{tabular}

Fuente: Dos Santos, Theotonio. \&El nuevo carácter de la dependencias, en $T$. Dos Santos, T. Vasconi et al., La nueva dependencia (Lima: Instituto de Estudios Peruanos, 1969), D. 19.

En consecuencia, las nuevas inversiones de capital, provenientes de las economías centrales, iniciaron un proceso de participación y virtual control de los mercados latinoamericanos, produciendo internamente y mediante la instalación de subsidiarias de las grandes corporaciones multinacionales, los productos industriales que antes se importaban; fenó-

15. Organización de Estados Americanos, América en cifras, vol. IIY, tomo 4 (1965). 
meno que adquiere un especial significado al no cancelar, pero sí modificar, la relación de dependencia: 'la relación típicamente comercial se transforma en una vinculación que se manifiesta primordialmente en el orden tecnológico-industrial, tipificando el "nuevo carácter de la dependencia». ${ }^{16}$

En México, el patrón de desarrollo asociado con el capital externo, a partir de la posguerra, representó la opción poz la que se decidirían la burguesía nacional y el Estado nexicano para bacer frente a los requeritrientos de capital y tecnología yue suponía la diversificación del sistema productivo hacia los sectores de bienes intermedios y de capital. Desde el punto de vista del nacionalismc económico, esta opción parecía no sólo aceptable sino también compatikle con los intereses de la nación: la pérdida de importancia de la inversión extranjera en la explotación de minerales, petróleo y otras actividad ss «tradicionales», fue interptetada como una afirmación de la sobetania nacional, al haber puesto bajo el control directo del Estado la explotación de los recursos naturales. En adelante, el capital externo sería encaminady a aquellas actividades industriales que ayudaran a «complementar» el ssfuerzo y la capacidad interna. Así planteado, los intereses externos eran coincidentes con los de los inversio nistas locales y con los de la nación en su conjunto, sin mostrarse que tal hecho ocurría dentro de situacicnes internacionales totalmente nuevas en las que el control interno de los recursos naturales era insuficiente, por sí mismo, para garantizar también el control nacional de aquellos sectores sobre los que giraría la nueva dir.ámica del desarrollo. ${ }^{17}$

16. Esta situación específica de: dependencia ha sido analizada para algunos pafses en profundidad. Para el caso byasileño, T. Dos Santos, «La crisis...», op. cit., y «La crisis de la teoria del desarrollo I' las relaciones de dependencia en América Latinas, en Helio Jaguaribe, Aldo Ferre:, et al, La dependencia politico-económica de América Latina (México: Siglo XXI, -.969). Véase en esta mistna obra la contribución de $H$. Jaguaribe, «Dependencia y autonomía en América Latina», la de Aldo Ferrer, «Industrias básicas, integración y corporaciones internacionales» y la de Miguel S. Wionczek, «El endeudamiento público externo y los cambios sectoriales en la inversión privada extranjeta de América Latina» Pata Chile, Oriando Caputo y Roberto Pizarro, Desarrollismo y capital extranjero (Sintiago de Chile: Ediciones de la Universidad Técnica del Estado, 1970). Un análisis más detallado sobre la problemática política y las relaciones de clase en Brasil, está en F. H. Carcoso, «Hegemonía burguesa e independencia económica: raíces estructurales de la crisis política brasileñan, en Brosil boy (México: Siglo XXI, 1968).

17. Un análisis crítico de este tiọo de nacionalismo económico puede consultarse en Wionczek, «La inversión privada norteamericana y el desarrollo de Mesoamérica», en Comercio Exterior, vol. XVIII, nú.n. 8 (1968), pp. 671-681. Como documento histórico sobre el debate de inversiones extranjexas en México, consúltese el vol. IX, núm. 1-2 de 1957, de la revista Problemas agrícolas e industriales de México, dedicado íntegtamente a este tema. 
«Papers»: Revista de Sociología

Así, las inversiones extranjeras no sólo aumentaron en México en forma acelerada, sino que, a la vez, el sector manufacturero se convirtió en su principal destinatario. De un total de 1.200 millones de dólares en que se estima la inversión extranjera para los últimos años del gobierno de Porfirio Díaz, casi el $80 \%$ se hallaba invertido en las industrias extractivas, incluyendo el petróleo, los ferrocarriles y los servicios públicos. En 1968, la minería concentraba únicamente el 6,0\% de la inversión extranjera total -estimada en más de 2.300 millones de dólares- y el petróleo el 1,8\%. En cambio, la industria manufacturera, de concentrar el 4,0\% de dicha inversión en 1911 y el 7,0\% en 1940, pasó a absor* ber el $26,0 \%$ en 1950 y el 74,2\% en 1968 , lo que revela, además de la magnitud de los cambios, el fuette impuiso que éstos recibieron a partir de la posguerra (Tabla 4).

Por otra parte, existe suficiente evidencia en el sentido de que del total de las mayores empresas extranjeras residentes en México en el año 1965 (247), el 65,59\% de ellas se fundaron en el período 1946-1965 instalándose 162 subsidiarias. De estas 162 empresas, el $75,87 \%$ se orientaron a la fabricación de bienes de capital (Tabla 5).

\section{TABLA 4}

Distribución sectorial de la inversión privada extranjera en México $1911-1968$

(Porcentajes)

\begin{tabular}{|c|c|c|c|c|c|}
\hline Sectores & 1911 & 1940 & 1950 & 1960 & 1968 \\
\hline Agricultura ... & 7,0 & 1,9 & 0,7 & 1,8 & 0,7 \\
\hline Minería $\ldots \ldots \ldots \ldots \ldots \ldots \ldots \ldots . . . . . .$. & 28,0 & 23,9 & 19,8 & 15,6 & 6,0 \\
\hline Petróleo,$\ldots \ldots \ldots \ldots \ldots \ldots \ldots \ldots$ & 4,0 & 0,3 & 2,1 & 2,0 & 1,8 \\
\hline Industria Manufacturera ...... & 4,0 & 7,0 & 26,0 & 55,8 & 74,2 \\
\hline Energía Eléctrica.....$\ldots \ldots \ldots$ & 8,0 & 31,5 & 24,2 & 1,4 & - \\
\hline Comercio $\ldots \ldots \ldots \ldots \ldots \ldots \ldots$. & 10,0 & 3,5 & 12,4 & 18,1 & 14,8 \\
\hline Comunicaciones y Transportes. & 39,0 & 31,6 & 13,3 & 2,8 & - \\
\hline Otros Servicios $\ldots \ldots \ldots \ldots \ldots . .$. & $\rightarrow$ & 0,3 & 1,5 & 2,5 & 2,5 \\
\hline
\end{tabular}

Fuente: Miguel Wionczek, *La inversión extranjera privada en México: Problemas y pers. pectivasy, en Comercio Exterior, vol. XX, núm. 10 (1970), p. 818. 


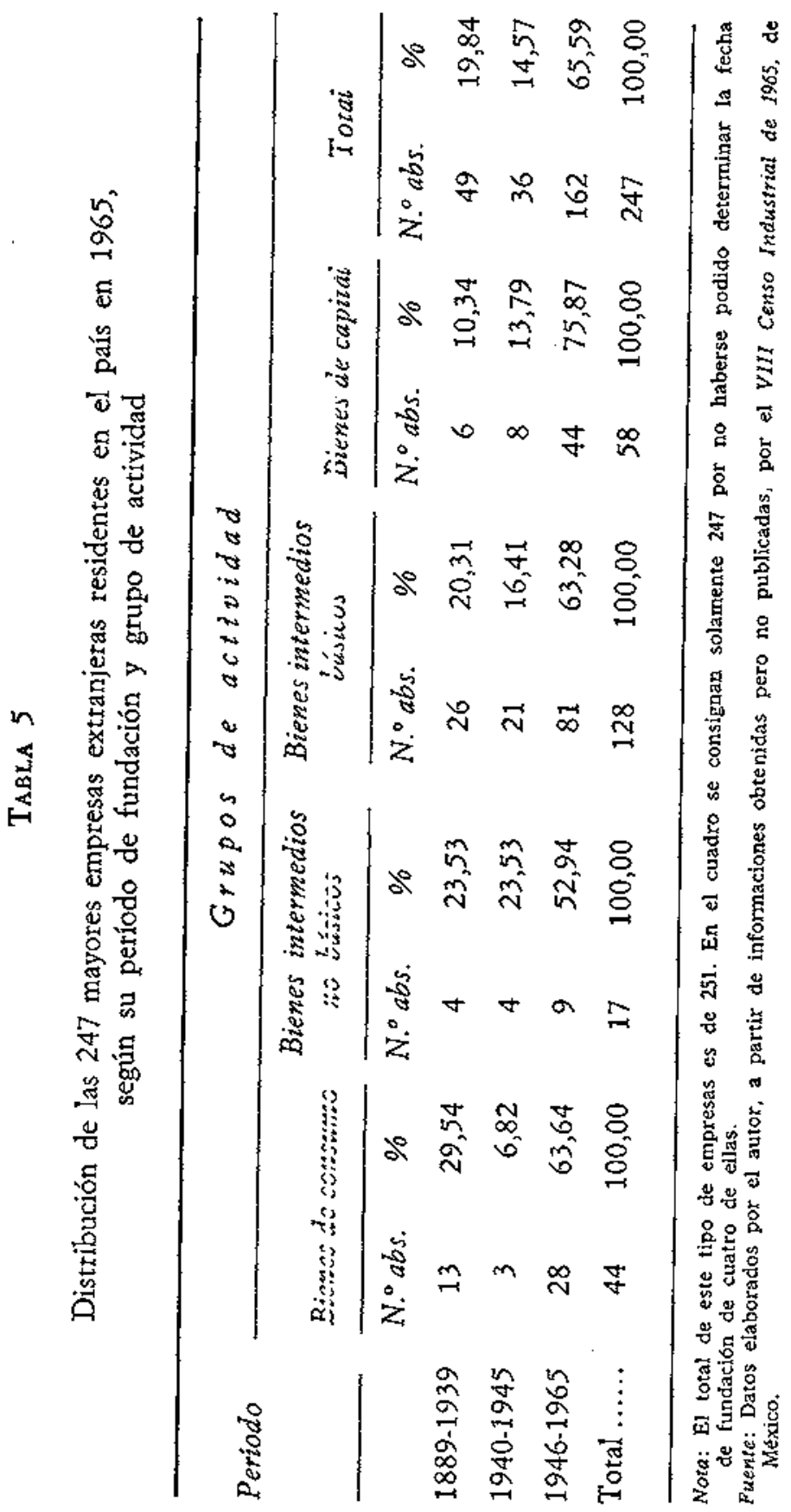


Igualmente, las cifras disponibles permiten apreciar la participación mayoritaria que el capital norteameticano posee dentro del total de la inversión extranjera en México, pues de 1.745 millones de dólares en que fue estimada dicha inversión para el año $1965,1.456$ millones, o sea el $83,43 \%$, pertenecian a empresas de los Estados Unidos. ${ }^{18}$

Los cambios observados en la magnitud y distribución sectorial de la inversión extranjera ponen de relieve la forma estructural a partir de la cual se integra una economía central en la estructura de una economía periférica, controlando internamente una parcela importante del mercado nacional y del aparato productivo, precisamente en su sector más dinámico. En otros términos, la telación centro-petiferia deja de expresarse mediante el enclave expottadot, al tiempo que cambia la división internacional del trabajo entre países productores de materias primas y países productores de manufacturas que caracterizaba la contradicción existente entre desarrollo y dependencia. En la nueva situación, en la que las economías centrales se orientan al sector manufacturero de la periferia, no sólo se hace posible el desarrollo sino que a la vez se mantienen, redefinidos, los lazos de la dependencia. En esta redefinición de la relación centro-periferia, se da paso al sistema capitalista industrial tal y como éste puede desarrollarse: en la periferia del mercado mundial y a la vez integrado a él. ${ }^{19}$ De ahí que el concepto de "economías industrial-periféricas» exprese de manera más adecuada —que el de «países en desarrollo», por ejemplo- el carácter estructural del actual desarrollo de ciertos páses latinoamericanos $y$, particularmente, el de México.

La industrialización nacional, dentro del nuevo catácter de la dependencia alteró, por su parte, las bases políticas y sociales del desarrollismo nacionalista en la misma medida en que la necesidad de acumulación de capital se presentaba, cada vez más, en contradicción con la tendencia tedistributiva implicada en la alianza original. La opción, hecha en favor de una rápida acumulación, se hizo posible gracias a un doble juego: abrir el mercado interno al capital externo y redefinit la orientación del proceso en favor de una acumulación basada en el mantenimiento de una desigual distribución del ingreso.

18. Miguel Wionczek, «La inversión extranjera privada en México: problemas y perspectivas», en Comercio Exterior, vol. XX, núm. 10 (1970), p. 818. Los datos sobre la participación del capital norteamericano en la inversión extranjera provienen de un estudio de Leopoldo Solís, Análisis de algunos aspectos de la inversión privada en México, trabajo presentado en el Seminatio sobre aspectos financieros de la integración de América Iatina, BID.INTAL, Buenos Aires, 1969.

19. F. H. Cardoso y E. Faletto, Dependencia..., op. cit., pp. 131 y 163-165. 
Los efectos de esta opción habrían de proyectarse, a su vez, en una doble tendencia: la pérdida creciente del control nacional de la industrialización, por ur lado, y, por otro, el gradual debilitamiento de la alianza vertical con los sectores populares, produciendo, en el mismo movimiento, la integración horizontal de los intereses de la burgueśa, en el plano económico y político, aliada a los intereses reptesentados por el capital extranjero. Ello no significa, según se vetá más adelante, la estructuración de un conglomerado monolítico de clase; por el contrario, el propio proceso contribuyó, y lo sigue haciendo, a la generación, como resultado, de «f́racciones burguesas marginales», excluidas del polo hegemónico del nuevo proceso. 20

Por lo que a los sectores populares se refiere, las expectativas de un desarrollo dexnoctático - con ir corporación creciente- se revirtieron, dentro del nuevo modelo, en una paralización, e incluso disminución, de sus niveles de consumo y participarión en el ingreso nacional, como resultado de una pauta de desarrollo en la que las metas de integración nacional, tanto regional como social, fueson perdiendo significación.

El desequilibrio tegional $"$ las diferencias sociales que lo acompañan se han agudizado cada vez más. De acuerdo con ciertos estudios, en las entidades más prósperas — con un ingreso promedio por habitante superiox a seis mil pesos anuales -.v.ve el $30 \%$ de la población, se genera el $59,6 \%$ del vaior total de lin producción de la industria de transformación, se gasta el $55,8 \%$ del gas to total conjunto de los gobiernos estatales, y el Instituto Mexicano del Sęuro Social (IMSS) ampara al $29,3 \%$ de la población total. ${ }^{21}$ En cambio, en las entidades de ingresos medio y bajo (24 entre un total de 32), doxde reside la mayor parte de la población nacional $(69,7 \%$ del total), dichos indicadores manifiestan la situación inversa (Tabla 6).

20. En efecto, dicha integració: de intereses no insinúa la homogeneización absoluta de los intereses económicos exi:tentes entre los diversos sectores de la burguesía, así como tampoco el que sea ideolćgicamente monolítica. «Teóticamente, el establecimiento de un sistema de alianzas (verticales y/u horizontales) no supone la inexistencia de tensiones entre las partes ni mucho menos que esas alianzas sean estables.» Véase sobre este punto, F. H. Cardoso, «Hegemonía burguesa e independencia económica: rafces estructurales de la crisis polittca brasileñas, op. cit., pp. 85-122.

21. Ifigetia $M$. de Navarrete, "La distribución del ingreso en México: tendencias y perspectivas», en El perfil de Mexico en 1980 (México: Siglo XXI, 1970), vol. 1. Igualmente, Kirsten Albretchsen, R ssa María Dominguez y Daniel Murayama, «Desarrollo desigual en México: 1900 y 1960", en Demografía y economía, vos. VI, núm. 1 (1972), donde se demuestra cómo ía desigualdad regional y social en México, entre 1900 y 1960 ha ido constantemente en aumento. 


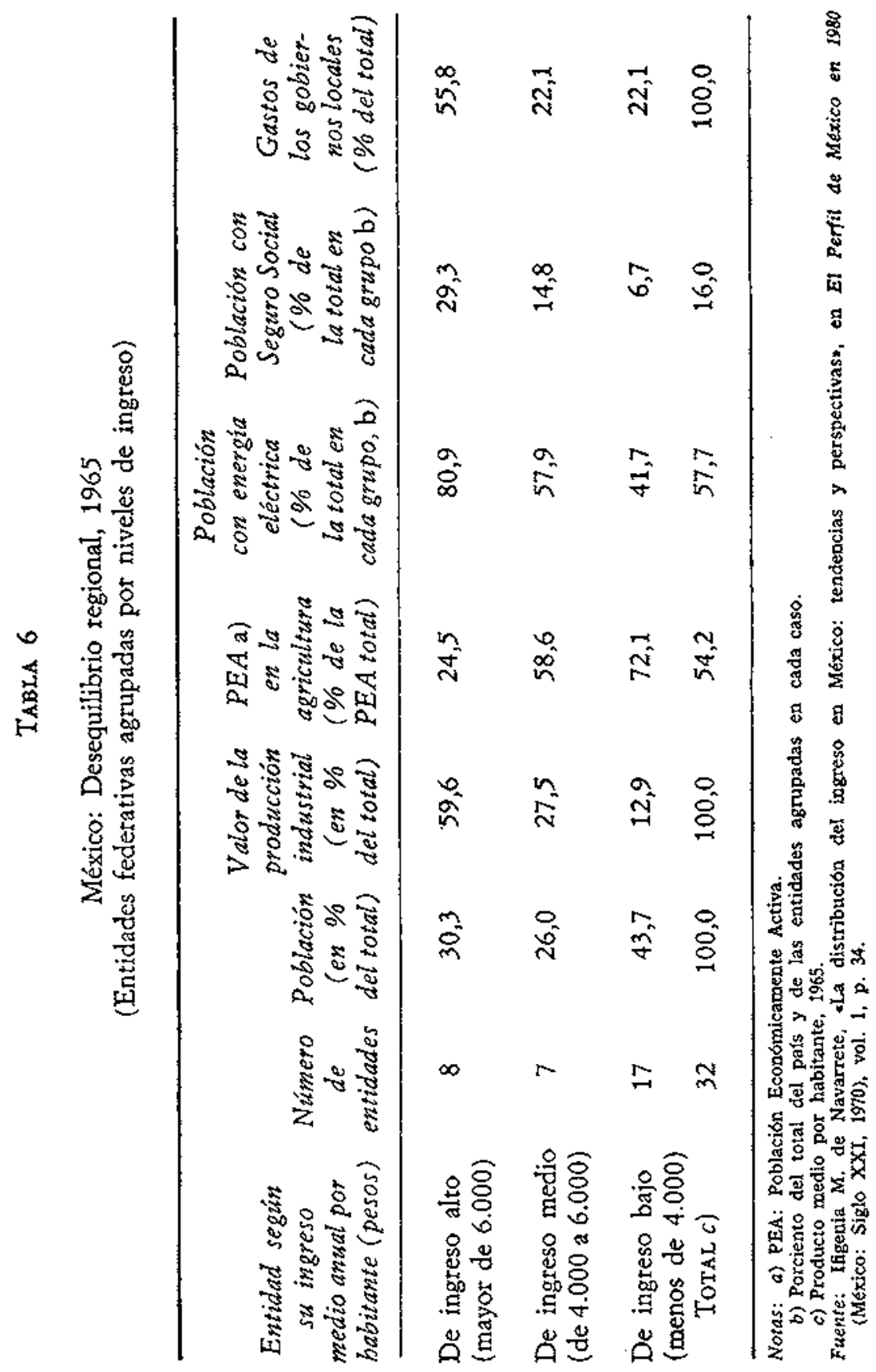


La fuerte desigualdad del ingreso puede también apreciarse en función de la participación que en el ingreso nacional tienen el factor trabajo y el factor capital; esto es, los ingresos derivados en forma de sueldos y salarios por comparación con los ingresos derivados de las utilidades. Desde el año 1939 en que el factor trabajo tuvo una participación del 53,6\% en el ingreso nacional, se inició un proceso decreciente cuyo nivel más baj̣o se tegistró en 1946 al fijar una participación del mismo factor de apenas el $39,2 \%$. Veinte años después; en 1966, la participación del factor trabajo apenas se había conseguido igualar en el nivel de 1939 at registrar un $53,1 \%,{ }^{22}$ de manera que durante todo el período de industrialización y crecimiento económico sostenido, la rentabilidad del capital ha sido desptoporcionadamente trayot a la del trabajo auspiciando una ampliación cada vez mayor de la brecha a pobres y a ticos y a la vida rural de la urbana.

Por otra parte, los eventuales cambios en la distribución del ingreso han tendido generalmente a favorecer a aguellos grupos sociales que por su posición en el ingreso podrian ser considerados como miembros de los sectores medios, en tanto que los ingresos de los sectores más bajos se han incluso deteriorado.

Así, como lo muestra la Tabla 7, el $50 \%$ de las familias con ingresos más bajos disminuyó su participación en el ingreso del 19,1\% en 1950 al $15,4 \%$ en $1963-64$.

\section{TABLA 7}

México: distribución del ingteso. 1950-1964

\begin{tabular}{cccc}
\hline $\begin{array}{c}\text { Porcentaje de familias } \\
\text { en orden decreciente } \\
\text { de ingresos }\end{array}$ & \multicolumn{3}{c}{ Porcentajes de ingresos } \\
\cline { 2 - 4 } 50 & 1950 & $1956-57$ & $1963-64$ \\
30 & 19,1 & 15,6 & 15,4 \\
20 & 21,1 & 23,0 & 26,1 \\
$5 \%$ más alto & 59,8 & 61,4 & 58,5 \\
$1 \%$ más alto & 40,0 & 36,5 & 29,0 \\
& 23,0 & 16,0 & 12,0
\end{tabular}

Fuente: CEPAL, Estudio sobre la disis ribución del ingreso en América Latina (E/CN. 12/no/ Add. 1), 1967.

22. David Ibarta, «Mercados...», op. cit., p. 117. 
En resumen, el desartollo económico se ha generado a costa de una marginalización creciente de los sectores populares, no del proceso sino de sus beneficios, y ha mantenido en muchos sentidos la fisonomía típica del subdesarrollo. ${ }^{23}$

Sin embargo, sería un erroz suponer que la nueva situación de dependencia no haya alterado también la posición estructural de la burguesía nacional e impuesto linitaciones a la constitución hegemónica de su liderazgo. De hecho, como se verá a continuación, el medio estructural en el que se definen actualmente las posibilidades de acción de la burguesía nacional y en particulat de las élites empresariales del sector industrial, reduce en forma considerable sus tentativas de autonomía y control, tanto como la propia emergencia de estas ideologías de «desarrollo nacional», entaarcándolas dentro de los límites de la nueva alianza desartollista e internacionalizada del proceso de desarrollo dependiente asociado.

\section{Estructura industrial y élites empresariales}

El grado de integración y consolidación de la industria que se fue logrando en el país a partir del proceso sustitutivo, condujo, de manera paralela, a la formación, dentro del ámbito de las clases productoras, de ciertas élites empresariales cuyas posiciones dentro del sistema industrial las coloca en una situación dominante. Los límites de dichas élites empresariales en el control del proceso económico pueden establecerse a partir del análisis de su participación dentro de la estructura productiva y de los grados de control que en ella le corresponden.

De acuerdo con la información publicada por el Censo Industrial de 1965 , la industria nacional estaba integrada por un total de 136.066 establecimientos industriales. De ellos, 1.117, o sea el $0,8 \%$ del total, controlaba el $64,28 \%$ de la producción bruta total de la industria $(\$ 121.560 .715 .000)$ con un valor que ascendía a los 78.141 .679 .000 pesos mexicanos. Por otra parte, la misma proporción de establecimientos controlaba el $66,34 \%$ del capital total invertido en la industria (\$95.664.020.000) con una inversión total de 63.471 .267 .000 pesos.

Sin embargo, desde el punto de vista de la mano de obra, dichos establecimientos daban empleo a solamente 480.853 trabajadores; es decir, a solo el $34 \%$ del personal ocupado en la industria que para ese año

23. Véase Ricardo Cinta, «Clases sociales y desarrollo en México», en Revista Latinoamericana de Ciencia Politica (1970). 
registró la cifra de 1.409 .894 trabajadores. Así, con únicamente la tetceta parte de la fuerza de trabajo industrial, menos del $1 \%$ del total de establecimientos controla las dos terceras partes del valor de la producción y del capital invertido (Tabla 8).

\section{TABLA 8}

Distribución de la producción bruta total, capital invertido y personal ocupado, por númer $>$ de establecimientos en $1965, a$ )

\begin{tabular}{|c|c|c|c|c|c|c|c|}
\hline \multirow{2}{*}{\multicolumn{2}{|c|}{$\begin{array}{c}\text { Número y } \\
\text { proporción de } \\
\text { establecimientos }\end{array}$}} & \multicolumn{6}{|c|}{ Grados de control } \\
\hline & & \multicolumn{2}{|c|}{ Produccion bruta total, b) } & \multicolumn{2}{|c|}{ Capital invertido, b) } & \multicolumn{2}{|c|}{ Personal ocupado } \\
\hline No. abs. & 96 & No. abs. & $\%$ & No. abs. & 96 & No. abs. & $9 \%$ \\
\hline $\begin{array}{r}134.949 \\
1.117\end{array}$ & $\begin{array}{r}99,18 \\
0,82\end{array}$ & $\begin{array}{l}43.419 .036 \\
78.141 .679\end{array}$ & $\begin{array}{l}35,72 \\
64,28\end{array}$ & $\begin{array}{l}32.192 .753 \\
63.471 .267\end{array}$ & $\begin{array}{l}33,66 \\
66,34\end{array}$ & $\begin{array}{c}929.041 \\
480.853\end{array}$ & $\begin{array}{l}65,90 \\
34,10\end{array}$ \\
\hline
\end{tabular}

Total:

$\begin{array}{llllllll}136.066 & 100,00 & 121.560 .715 & 100,00 & 95.664 .020 & 100,00 & 1.409 .894 & 100,00\end{array}$

Notas: a) Incluye industrias extractivis y de fransformacion.

b) Millares de pesos.

Fuente: VIIl Censo Industrial, 1966 (México: SIC, 1967).

Estos 1.117 establecimientos, cuya producción individual es superior a los 20 millones de pesos, re oresentan el total de establecimientos regis. trados en el Censo Industrial con esta característica y se encuentran constituidos en 938 empresas, a lis que si se agrega su propiedad de otros establecimientos de menor importancia telativa, contarían entonces con un total de 1.243 establecimiento: (el $0,91 \%$ del total de la industria) controlando, entonces, una cantida 1 algo superior a la descrita.

No obstante el alto grado de concentración dei poder económico que estos datos revelan, es preciso apreciar, en otra presentación, la forma como se distribuye este pode: tanto entre los diversos tamaños de las emptesas, cuyo rango de variación sigue siendo muy amplio, así como entre los distintos grupos que conforman la élite industrial: los inversionistas extranjeros, los empresarios locales y las empresas del Estado.

Al clasificar a las 938 emprresas industriales en función de su tamaño, 
de mayor a menor, se hace manifiesta la desigual participación de las empresas en el control del aparato productivo. El estrato compuesto por las diez mayores empresas controla el $17,73 \%$ del valor de ia producción de las 938 y el $10,99 \%$ de las que corresponde al total del país. Las primeras cien empresas representan el $49,45 \%$ de la producción conjunta de las $938-30,61 \%$ de la del país-y a las 300 mayores cortesponde el $72,16 \%$ y el $44,70 \%$ de la producción de las 938 y del país, respectivamente.

Esto significa que las 110 primeras empresas $(11,69 \%$ de las 938$)$ ejercen el control del $51,25 \%$ de la producción conjunta total y del $31,72 \%$ del total de la producción industrial del pais, frente a las 828 empresas restantes $(88,31 \%$ de las 938$)$ que controlan el $48,75 \%$ de la producción conjunta y el $30,23 \%$ de la producción nacional de la industria (Tabla 9).

\section{TABLA 9}

Estratificación de las 938 empresas industriales más grandes del país, de acuerdo con el valor de su producción bruta total, a)

\begin{tabular}{cccc}
\hline Número de & \% respecto a las & \multicolumn{1}{c}{$\begin{array}{c}\text { Control de la producción } \\
\text { bruta total (\%) }\end{array}$} \\
\cline { 3 - 4 } & 938 empresas & De las 938 & Del país \\
10 & 1,06 & 17,73 & 10,99 \\
100 & 10,63 & 49,45 & 30,61 \\
300 & 31,89 & 72,16 & 44,70 \\
938 & 100,00 & 100,00 & $61,95,6)$ \\
El 11,69 \% de las empresas: & & 51,25 & 31,72 \\
El 88,31 \% restante: & & 48,75 & 30,23 \\
\hline
\end{tabular}

Notas: a) Salvo especificación en contrario. todos los datos que se refleren a las 938 empresas industriales más grandes dei país, han sido obtenidos y elaborados especialmente por el autor, a través de investigación directa en diversos organismos públicos y privados, durante la investigacion que ha estado dirigiendo para el Colegio de Mexico y la Comisión Económica para América Latina (CEPAL) sobre El empresario industrial y el desarrollo economico de México. El universo constituido por las 938 mayores empresas industriales del país, proviene del análisis del codigo del Censo Industrial de 1965, en el cuai no fueron tabuladas ni publicadas estas informaciones.

b) En este cuadro, el control de las 938 empresas sobre el valor de la producción bruta total del pais no es del $64,28 \%$ por referirse exclusivamente a la industria de transformación, excluyendo la industria extractiva. 
Por otra parte, el análisis de los intereses representados por este sector dominante del sistema industrial permite percibir de manera más clara el grado de participación que corresponde a los distintos grupos elitistas de la industria, tanto por lo que se refiere a las posiciones logradas por el Estado y el sector empresaria de la burguesía local, como por lo que atañe a las posiciones adquiridas por el capital extranjero a partir de la posguerra, a través de las subsidiarias de las grandes corporaciones transmacionales.

De las 938 emptesas industriales que se analizan en este trabajo, el $26,7 \%$ son extranjeras, el $5,30 \%$ estatales y el $68 \%$ restante pertenecen al sector privado nacional..$^{24}$ Apıırentemente, entonces, en cuanto al número total de grandes empresas indıstriales funcionando en el país, existe un claro dominio nacional, pues entre el sector privado y el sector estatal se controla el $73,3 \%$ del total.

Sin embargo, al introducij criterios adicionales, la impresión de que existe un amplio sector de la industria controlado nacionalmente pierde su impacto inicial. ¿En qué estratos de la producción tienden a concentrarse uno y otro tipo de empresas? ¿Cuáles predominan en los estratos superiores? Desde esta perspectiva, o sea considerando la importancia relativa de los tres tipos de empreses en cuanto a la magnitud de su producción bruta total, las empresas extrinjeras adquieren una importancia mucho mayor.

De las primeras 10 empreias, el $50 \%$ son extranjeras; de las primeras 20 lo son el $55 \%$ y de las primeras 50 , to es el $48 \%$. De las pri. meras 110 , que como se mostró controlan el $51,25 \%$ del valor de la producción total de las 938 er upresas, son extranjeras el $47 \%$ y de las 300 primeras lo es el $34,7 \%$. Así, los datos indican una clara concentra. ción de la empresa extranjera centro de las grandes unidades productoras, con alta densidad de capital y laja utilización de mano de obra, tendencia exactamente opuesta a la segitida por la mayor parte de las empresas bajo control del sector privalo nacional $y$, muy particularmente, por aquellas cuya importancia relativa les atribuye una posición no elitista (Tabla 10).

24. La clasificación de las empresas en estatales, extranjeras y privadas nacio. nales fue elaborada a partir del tipo de capital predominante, de acuerdo con informaciones y clasificaciones no publicadas y obtenida de diversas fuentes, mediante investigación directa. Entre ellas, Nacional Financiera, S. A. (1970); Business Trends (1968. 1970), Cámara Americana de Comєrcio (1966); Secretaría de Relaciones Exteriores (1970); Confederación Nacional de Gámaras Industriales (1970) y Confederación Patronal de la República Mexicana (1970). 
«Papers»: Revista de Sociología

\section{Tabla 10}

Distribución de las 938 empresas industriales más grandes del país, según la composición de su capital, por estratos

Grado de control del valor de la producción bruta total (\%)

\begin{tabular}{lcccc} 
Estrato & Extranjeras & Estatales & Privadas nacionales & Total \\
\hline $1-10$ & 50,00 & 20,00 & 30,00 & 100,00 \\
$1-20$ & 55,00 & 15,00 & 30,00 & 100,00 \\
$1-50$ & 48,00 & 22,00 & 30,00 & 100,00 \\
$1-100$ & 47,00 & 13,00 & 40,00 & 100,00 \\
$1-110$ & 47,00 & 13,00 & 40,00 & 100,00 \\
1.300 & 34,70 & 9,70 & 55,60 & 100,00 \\
$1-500$ & 31,00 & 7,40 & 61,60 & 100,00 \\
$1-938$ & 26,70 & 5,30 & 68,00 & 100,00 \\
& & & &
\end{tabular}

Si se examina ahora la localización de la inversión extranjera desde el punto de vista del control de ciertos productos considerados «estrategicos» para el impulso de la industrialización, puede observarse que en et control de este tipo de recursos el capital extranjero adquiere una participación decisiva.

En este sentido, la apertura del mercado interno al capital extranjero posibilitó, en efecto, la continuación de un proceso sustitutivo que no podía detenerse en su primera etapa. Sin embargo, la sustitución de bienes intermedios y de capital se dejó en manos de las subsidiarias extranjeras, que con ese fin fueron instalándose en el país, de tal modo que a partir de la posguerra la inversión extranjera no sólo se reorientó hacia el sector manufacturero, sino que además lo hizo hacia aquellas ramas productivas que toás contribuyen a dar dinamismo al proceso de industrialización.

Del total de las 938 grandes empresas industriales del pais, 116 $(12,4 \%)$ son productoras de bienes de capital, de las cuales el $53,0 \%$ (61 empresas) son extranjeras. A la producción de bienes intermedios bá. sicos, se dedican 311 empresas, de las cuales $130(41,8 \%)$ son también extranjeras. Por tanto, de 427 empresas productoras de bienes intermedios 
Burguesía nacional, el caso de México

\section{'FABLA 11}

Distribución de las 938 máyores empresas industriales del país, según la composición de su capital y grupo de actividad

\begin{tabular}{|c|c|c|c|c|c|c|c|c|}
\hline \multirow{3}{*}{ Grupo de actividad } & \multirow{2}{*}{\multicolumn{2}{|c|}{$\begin{array}{l}\text { Numero ae } \\
\text { empresas }\end{array}$}} & \multicolumn{6}{|c|}{$\begin{array}{l}\text { Control de las empresas según } \\
\text { la composición del capital }\end{array}$} \\
\hline & & & \multicolumn{2}{|c|}{ Extranjero } & \multicolumn{2}{|c|}{ Estatal } & \multicolumn{2}{|c|}{$\begin{array}{l}\text { Privado } \\
\text { nacional }\end{array}$} \\
\hline & $\begin{array}{l}\text { No. } \\
\text { abs. }\end{array}$ & $\%$ & $\begin{array}{l}\text { No. } \\
\text { abs. }\end{array}$ & $\%$ & $\begin{array}{l}\text { No. } \\
\text { abs. }\end{array}$ & $\%$ & $\begin{array}{l}\text { No. } \\
\text { abs. }\end{array}$ & $\%$ \\
\hline Bienes de capital, a) & 116 & 12,4 & 61 & 53,0 & 5 & 4,3 & 50 & 42,7 \\
\hline $\begin{array}{l}\text { Bienes intermedios } \\
\text { básicos, } b \text { ) }\end{array}$ & 311 & 32,2 & 130 & 41,8 & 13 & 4,2 & 168 & 54,0 \\
\hline $\begin{array}{l}\text { Bienes intermedios } \\
\text { no básicos, } c \text { ) }\end{array}$ & 174 & $1 \varepsilon, 5$ & 16 & 9,2 & 11 & 6,3 & 147 & 84,5 \\
\hline Bienes de consumo, $d$ ) & 337 & 35,9 & 44 & 13,1 & 21 & 6,2 & 272 & 80,7 \\
\hline To'TALES, $e$ ) & 938 & $10(1,0$ & 251 & 6,7 & 50 & 5,3 & 637 & 68,0 \\
\hline
\end{tabular}

Notos: a) Incluye: Constracción y repa ación de maquinaria, excepto la eléctrica (rama 36): construccion y reparación de maquinaria, aparatos, accesorios y artículos eléctricos y electrónicos (rama 37) y construccitn, ensamble y reparación de equipo y material de transporte (rama 38).

b) Incluye: Fabricación y reparación de productos de hule (rama 30); fabricacion de productos quimicos (rama 31); fabricación de productos derivados del petróleo y del carbon mineral (rama 32); fabricación de o ros productos de minerales no metálicos (rama 33): industrias metálicas básicas (rama $: 4$ ); fabricación y reparacíon de productos rnetálicos, excepto maquinaria y equipo de trinsporte (rama 35 ).

c) Incluye: Fabricación de textiles (rama 23); industrias que utilizan preferentemente madera y corcho, excepto la fabricacion de muebles (rama 25); fabricación de papel y productos de papel (rama 27); industrias de! iuero, productos de cuero, piel y materiales sucedáneos, excepto prendas de vestir (rania 29).

d) Incluye: Manufactura de productos alimenticios, exsepto bebidas (rama 20); elaboracion de bebidas (rama 21); fabricacion di: productos de tabaco (rama 22); fabricacion y reparación de calzado, otras prendas de vestir y artículos confeccionados con textiles (rama 24); fabricación de muebles de madera (rama 26); imprentas editoriales e industrias conexas (rama 28); industrias manufactureras diversas (rama 39).

e) La agrupación de las ramas de actividad por grupos se elaborb de acuerdo con la clasificación, a nivel de dos dígitos, deI VIII Censo Industrial de 1965. 
básicos y de capital, 191 de ellas son extranjeras, esto es, el $44,73 \%{ }^{25}$ En apariencia, la inversión extranjera pierde, en cambio, su importancia cuando se trata de la producción de otro tipo de bienes, puesto que de las 174 empresas productoras de bienes intermedios no básicos, sólo participa con 16 de ellas $(9,2 \%)$ y de 337 empresas dedicadas a la fabricación de bienes de consumo controla sólo el $13,1 \%$ con 44 empresas (Tabla 11).

Si se distribuye a las empresas productoras de bienes de capital por estratos, de mayor a menor, la importancia del sector extranjero se revela aún mayor. Tomando sólo las 200 de mayor tamaño de entre las 938 , puede observarse que en el estrato de las primeras 10 no participa ninguna empresa nacional productora de bienes de capital, ni privada ni estatal, habiendo en cambio 3 extranjeras. En el estrato de las primeras 50 empresas, hay 8 extranjeras, 3 estatales y cero del sector privado nacional. En las primeras 100 , se localizan 11 extranjeras, 3 estatales y hasta entonces aparece 1 del sector privado nacional. Finalmente, en el estrato de las 200 mayores empresas, se encuentran 16 extranjeras, 4 estatales y 7 nacionales del sector privado.

En síntesis, en la producción de bienes de capital hay un fuerte predominio del capital extranjero, tanto en cuanto al número de empresas, como en lo que se refiere - sobre todo- al control de la producción. Le sigue en importancia el sector estatal, que aumenta en número de empresas conforme disminuye la importancia del estrato. Por su parte, el sector privado nacional sólo adquiere significado dentro de los estratos con una producción relativamente inferior, pese a que en el total de empresas pro. ductoras de este tipo de bienes participe con el $42,7 \%$ de las mismas (Tabla 12).

25. Las ramas han sido agrupadas de acuetdo con el uso más importante de sus productos. Otra clasificación - muy semejante a la presentada en este trabajo- puede verse en Joel Bergman, Industrialization: Past Success and Future Problems, citado en Leopoldo Solís, La realidad económica mexicana: retrovisión y perspectivas (México: Siglo XXI, 1970), p. 222. Las ramas industriales incluidas en los distintos grupos de actividad se indican al pie del Cuadro núm. 11. 
Distribución de las mayores enıpresas productoras de bienes de capital extranjeras, estatales y rrivadas nacionales, por estratos

$(10(\% ; 116) a)$

\begin{tabular}{|c|c|c|c|c|c|c|}
\hline \multirow{3}{*}{ Estrato } & \multicolumn{6}{|c|}{ Control de la producción de bienes de capital } \\
\hline & \multicolumn{2}{|l|}{ Extranjeras } & \multicolumn{2}{|l|}{ Estatales } & \multicolumn{2}{|c|}{ Privadas nacionales } \\
\hline & No. de empresas & $\%$ & No. de empresas & $\%$ & No. de empresas & $\%$ \\
\hline $1-10$ & 3 & 3,0 & 0 & 0 & 0 & 0 \\
\hline 1.50 & 8 & 7,0 & 3 & 3,0 & 0 & 0 \\
\hline $1-100$ & 11 & 9,5 & 3 & 3,0 & 1 & 0,8 \\
\hline $1-200$ & 16 & 13,8 & 4 & 3,4 & 7 & 6,0 \\
\hline
\end{tabular}

Nora: a) Total de empresas en el estra:o de las primeras 200: 27.

Considérese, por último, è modo como se estratifican las empresas dentro de los grupos cuya actividad se dirige a la fabricación de bienes intermedios y de consumo.

Mientras en el caso de los jienes intermedios básicos aparece una relación de ciexto equilibrio - en el estrato de las 200 más grandes--entre el sector extranjero y el privad s nacional, si se observa el estrato de las primeras 100 la diferencia en favor del sector extranjero se revela más significativa, puesto que contro.a un $16,92 \%$ (22 empresas) contra el $8,91 \%$ que le corresponden en este estrato al sector privado nacional (Tabla 13).

En cuanto a los bienes in ermedios no básicos, el control nacional, sobre todo por parte del secto: privado, adquiere una importancia mayor a la que le corresponde en el ca:o de los anteriores grupos de actividad, si bien se trata de productos cuya importancia relativa es quizá menor que 
«Papers»: Revista de Sociología

\section{TABLA 13}

Distribución de las mayores empresas productoras de bienes intermedios básicos, según la composición de su capital, por estratos

$$
(100 \%: 311) a)
$$

\begin{tabular}{|c|c|c|c|c|c|c|}
\hline \multirow{3}{*}{ Estrato } & \multicolumn{6}{|c|}{ Control de la producción de bienes intermedios básicos } \\
\hline & \multicolumn{2}{|l|}{ Extranjero } & \multicolumn{2}{|l|}{ Estatal } & \multicolumn{2}{|c|}{ Privado nacional } \\
\hline & No. de empresas & $\%$ & No. de empresas & $\%$ & No. de empresas & $\%$ \\
\hline $1-10$ & 1 & 0,3 & 1 & 0,3 & 2 & 0,6 \\
\hline $1-50$ & 11 & 3,5 & 5 & 1,6 & 6 & 1,9 \\
\hline $1-100$ & 22 & 7,1 & 5 & 1,6 & 15 & 4,8 \\
\hline $1-200$ & 37 & 11,9 & 7 & 2,3 & 44 & 14,1 \\
\hline
\end{tabular}

Nota: a) Total de empresas en el estrato de las primeras 200: 88.

la del renglón de productos básicos. Su participación se observa en la Tabla 14.

\section{TABLA 14}

Distribución de las mayores empresas productoras de bienes intermedios no básicos, según la composición de su capital, por estratos

$(100 \%$ : 174) a)

\begin{tabular}{|c|c|c|c|c|c|c|}
\hline \multirow{3}{*}{ Estrato } & \multicolumn{6}{|c|}{ Control de la producción de bienes intermedios no básicos } \\
\hline & \multicolumn{2}{|l|}{ Extranjero } & \multicolumn{2}{|l|}{ Estatal } & \multicolumn{2}{|c|}{ Privado nacional } \\
\hline & No. de empresas & $\%$ & No. de empresas & $\%$ & No. de empresas & $\%$ \\
\hline $1-10$ & 0 & 0 & 0 & 0 & 0 & 0 \\
\hline $1-50$ & 1 & 0,6 & 1 & 0,6 & 5 & 2,9 \\
\hline $1-100$ & 4 & 2,3 & 2 & 1,1 & 9 & 5,2 \\
\hline $1-200$ & 7 & 4,1 & 6 & 3,4 & 14 & 8,0 \\
\hline
\end{tabular}

Nota: a) Total de empresas en el estrato de las primeras 200: 27. 
Por último, también en las empresas productoras de bienes de consumo se aprecia, como lo muest:a la Tabla 15, una participación significativa del sector nacional y especialmente de su control privado.

\section{T ABLA 15}

Distribución de las mayores empresas productotas de bienes de consumo, según la composició: de su capital, por estratos

(100\%: 337) a)

\begin{tabular}{|c|c|c|c|c|c|c|}
\hline \multirow{3}{*}{ Estrato } & \multicolumn{6}{|c|}{ Control de la producción de bienes de consumo } \\
\hline & \multicolumn{2}{|l|}{ Extranjero } & \multicolumn{2}{|l|}{ Estatal } & \multicolumn{2}{|c|}{ Privado nacional } \\
\hline & No. de empresas & $\%$ & No. de empresas & $\%$ & No. de empresas & $s \%$ \\
\hline $1-10$ & 0 & 0 & 1 & 0,3 & 1 & 0,3 \\
\hline $1-50$ & 4 & 1,2 & 2 & 0,6 & 4 & 1,2 \\
\hline $1-100$ & 12 & 3,4 & 3 & 0,9 & 15 & 4,5 \\
\hline $1-200$ & 15 & 4,5 & 7 & 2,1 & 38 & 11,3 \\
\hline
\end{tabular}

Nota: a) Total de empresas en el estratc de las primeras 200: 60 .

De las informaciones aludidas es posible concluir que, en efecto, el capital extranjero no sólo ejerce un fuerte control dentro del sistema pro ductivo del país, sino que, ademís, dadas sus posiciones de relativa hegemonía dentro de ciertos puntos clave de la producción para el metcado interno -bienes intermedios básicos y de capital- ${ }_{,}^{26}$ ejerce a su vez el control de un mercado de carácter oligopólico, si no monopólico. No se trata de un capital "complementurio», sino competitivamente dominante.

Este hecho subraya el modo característico de operación de la economía industrial periférica, que bajo los efectos de la internacionalización del mercado interno, hace depender su funcionamiento de las grandes unida-

26. De las 251 emprasas extrarjeras que se encuentran dentro de las 938 mayores del país, 207, o sea el $82,4 \%$, se coni:entran en la produccion de bienes intermedios - básicos y no básicos- y de capital, lo que pone de manifiesto el interés que por este tipo de actividades ha tenido la jr.versíón extranjera en México. 
des productoras monopolistas internacionales que poseen una alta capacidad tecnológica y de capital. Sin embargo, lo relevante de esta situación no consiste simplemente en la descripción y el señalamiento de una evidente dominación externa, sino, como lo han hecho notar Cardoso y Faletto, «en la caracterización de la forma que asume y de los distintos efectos que ejerce, con referencia a las situaciones pasadas, este tipo de relación de dependencia sobre las clases y el Estadon."

Los datos presentados indican, en efecto, limitaciones relativamente precisas a la posibilidad de impulsar un proceso de industrialización que al tiempo que sea controlado nacionaimente, suponga la suficiente autonomía por parte de la burguesía nacional y del Estado para desarrollar una acción que a la vez que garantice la continuidad del crecimiento sea compatible con las aspiraciones de integración nacional e incorporación de cada vez más amplios sectores sociales. Esto es, las condiciones estructurales en que se procesa la industrialización en las economías periféricas, hacen depender a las élites locales del establecimiento de un nuevo tipo de alianza - desarrollista e internacionalizada- - en la que encuentran tanto las posibilidades de obtener lo que se proponen, cuanto los límites a su participación, aun dentro de su propio país. A la dominación entre naciones corresponden, así, formas específicas de dominación entre clases, inter e intranacionalmente referidas, que tipifica el modo como se constituye «el pro. blema nacional» en la periferia del sistema.

\section{Burguesia nacional y desarrollo}

Las condiciones históticorestructurales en que se ha desarrollado la burguesía nacional a partir de la crisis del 29 y el modo como sus posiciones fueron redefinidas a partit de la nueva situación de dependencia, sugieren una serie de posibilidades en la explicación de la diversificación de intereses que parece caracterizar su composición actual, no sólo en fun. ción de sus vinculaciones con los intereses externos, sino a partir también de su estratificación interna.

De hecho, las etapas de la industrialización sustitutiva imprimieron ciertas características a las empresas que surgieron o se expandieron en uno y otto momento, y este hecho contribuyó a definir, a la postre, su posición y función dentro de la estructura productiva del país y su modo de relación con el mexcado.

27. F. H. Cardoso y E. Faletto, Dependencia..., op. cit., p. 163. 
Existen suficientes elementis para considerar que las empresas productoras de bienes de consumo final surgieron principalmente durante la etapa de «sustitución fácil y forzosa» de importaciones, que supuso una alta participación de Ia inversión interna, en tanto que las empresas dedicadas a la fabricación de bienes intermedios y de capital lo hicieron en una etapa posterior y con una particijación creciente de la inversión extranjera. Este primer señalamiento establece, pues, una doble diferencia, asociada al periodo de fundación como viriable de base: por una parte, en ctanto al tipo de producto; por otra, en cuanto a la importancia relativa del capital interno o externo, en el control de las empresas.

Por otra parte, es posible es tablecer una segunda diferencia por lo que a la forma de apropiación del tzercado se refere, pues si bien es cierto que ambos tipos de empresas brsan predominantemente sus posibitidades de expansión en el crecimiento del mercado interno - lo que es catacterístico de la nueva situación de dependencia-, para algunas de ellas dicho crecimiento depende de la contizua incorporación de grupos de consumidores, sobre todo de los sectore; populares urbanos y de clase media, y, por tanto, descansan más en el tamaño absoluto de un mercado - característica de la etapa inicial de sustitución- del que buscan apropiarse extensivamente. Por el contratio la ampliación del mercado interno, para el caso de las empresas asociadas: al segundo período sustitutivo, depende sólo de manera indirecta de su crecimiento absoluto, descansando, más bien, en los factores que hacen posible la existencia de un mercado que, aunque numéricamente reducido, posea una alta capacidad de compra, esto es, el constituido por un númerc reducido de consumidores -individuos, familias o empresas- cuya participación en el ingreso es, en cambio, sumamente importante. De ahí que este tipo de empresas se orienten en favor de una apropiación intensiva de. mercado interno, mediante una estrategia de venta dirigida al segmento superior de la curva de Ia demanda.

Es evidente que el tipo de producto y la forma de apropiación del mercado que a él corresponde son dos características o atributos que se relacionan de maneta directa con el tamaño y funcionamiento de las empresas, distinguiéndolas cuantitat va y cualitativamente, ya sea en función del capital invertido, del volumet de la mano de obra empleada, del valor de la producción, etc., y de acuerdo con las características asociadas al nivel y tipo de operación tecnológica, los niveles de calificación de la mano de obra contratada, etc. ${ }^{28}$

28. En conjunto, tstas diferenci as, que vinculan a los empresatios a distintos tipos de intereses, parecen haber estaclo presentes en las diferencias doctrinarias que 
Sin embargo, sería apresurado pensat que las diferencias sefialadas entre las empresas industriales y las características que a cada tipo de ellas corresponden, bastan para comprender la naturaleza de las situaciones alrededor de las cuales giran las orientaciones económicas y políticas de la burguesía industrial.

Si bien es posibie afirmar que tales características de la empresa ejercen un peso importante en la actitud y el comportamiento empresarial, ello no significa que el proceso de decisiones en que se funda tal conducta no sea considerablemente más complejo de lo que se podría suponer si sólo se tiene en cuenta a la empresa aislada. De hecho, el desartollo económico del país ha estado caracterizado por una clara tendencia a la formación de «grupos económicos» que a la vez que amplían el área de acción económica del empresario mediante los mecanismos de integración horizontal y vertical, lo vinculan a un sistema de intereses considerablemente más diversificado y en el que la fusión del capital industrial y el financiero cobra lugar. ${ }^{29}$

Este hecho obliga, necesariamente, a adoptar la precaución metodo lógica de no inferir, mecánica y simplistamente, la explicación de las orientaciones y comportamientos de la élite empresarial, a partir de una unidad que, como la empresa, ha dejado de ser, en muchos aspectos, la unidad de análisis básica. El «grupo económico» constituye una unidad de mediación fundamental entre el nivel de la empresa y los rasgos estructurales del desarrollo dependiente. Por lo tanto, empresa y grupo econbmico constituyen realidades empíricas distintas, y esta diferencia, aunada a las indi.

durante mucho tiempo distinguieton en México a la Cámara Nacional de la Industria de Transformación (CNIT), en la que predominan las empresas de tamaño mediano y pequeño, productoras de bienes de consumo, con baja densidad de capital, escasa tecnología y abundante mano de obra, de otras organizaciones empresariales donde el peso de las grandes empresas, con características opuestas, ha sido mucho mayor. Véase: Robert Scott, Mexican Govermment in Transition (University of Tllinois Press, 1964) y Sanford Mosk, Industrial Revolution in Mexico (University of California Press, 1954).

29. En México, prácticamente no existen estudios sobre la formación de grupos económicos. Los resultados generados por la sociología brasileña sobre este tema sig. nifican una ayuda considerable, sobre todo en su aspecto metodológico. Véase al respecto los trabajos de Mauricio Vinhas de Queiros, Luciano Martins y J. A. Pessoa de Queiros, en el vol. II, núm, 1, de 1965 de la Revista do Instituto de Ciencias Sociats; y Luciano Martins, Industrialização, burguesia nacional e desenvolvimento (Río de Janeito: Editora Saga, 1968). También, Nathaniel H. Leff, «El espíritu de empresa y la organización industrial en los países menos desarrollados: los "grupos"”, en El trimestre económico, vol. XLI (3), núm. 163 (1974). 
cadas entre las empresas, debe tenerse presente en todo esfuerzo interpretativo. $^{30}$

Además, las modificaciones estructurales de las empresas industriales nacionales, asociadas a las carzcterísticas del proceso de sustitución de importaciones, posibilita también la exploración de las formas en que el proceso dependiente se expresa al nivel de la empresa, especialmente a partir del momento en que el faso a la sustitución de bienes intermedios y de capital no sólo produjo la inserción de las corporaciones multinacionales en el interior de la economía periférica, sino también indujo a un nuevo tipo de vinculaciones cor. el exterior a las empresas nacionales que lograron arribar a esta fase sus itutiva.

Este nuevo tipo de vinculición se originó en las nuevas necesidades de orden tecnológico y magnit $x d$ de los recursos financieros, correspondientes a la expansión del proseso productivo y se tradujo -en grados variables - en la pérdida de a tonomía, o por lo menos en el debilitamiento, del carácter propiamente nacional de las empresas locales y las fracciones empresariales a ellas asociadas. Esencialmente, esta vinculación de dependencia estructural a nivel de la empresa y del grupo económico podría ser expresada, técnicamer te, a través de un índice jerárquico -como el de la escala tipo Guttman- en el cual el control accionario, Ia vinculación financiera y el pago de k:zow-bow, patentes y royalties expresarían la forma determinada en que se manifiesta esta vinculación. ${ }^{31}$

En síntesis, la reorganización de la economía, impuesta por el avance de la industrialización, significó modificaciones apreciables en la composición y diversificación de los intereses de la élite empresarial a la vez que se definieron los límites que istablecen la «autonomía relativa» de los sectores que la constituyen: el sector privado nacional (en sus fracciones dependientes y autónomas), el sector estatal y el sector extranjero, cuyas respectivas posiciones de contro del proceso de desarrollo se han analizado anteriormente y en la que la sracción nacional «autónoma» difícilmente participa, aunque sea elitista, de la alianza hegemónica que, en la expresión de F. H. Cardoso, ${ }^{32}$ constituye el «trípode» del desarrollo económico: el

30. Mauricio Vinhas de Queitos ha definido la expresión «grupo económico» como «todo conjunto estable y telat vamente poderoso de firmas relacionadas entre sí por el capital y el poder de decisión de dirigentes comunes».

31. Estas técnicas han sido usaulas, con los mismos propósitos, por F. H. Cardoso, Ideologias de la burguesia industrial en sociedades dependientes (Argentina y Brasil), op. cit., y Vilmar Faria, «Dependencia e ideología empresarial», en Revista Latinoamericana de Ciencia Politica, vol. .I, núm. 1 (1971).

32. F. H. Cardoso, Cuestiones de sociologia del desarrollo de América Latina, op. cit., p. 153. 
Estado, las corporaciones multinacionales y la burguesía internacionalizada. Así, la actual composición de la burguesía nacional no sólo se caracteriza por un alto grado de heterogeneidad interna, basada sobre todo en las distintas posibilidades de acceso a posiciones de cierta hegemonía que se hallan adscritas a la importancia relativa de los productos, el tamaño de las empresas, sus tipos de metcado, su constitución en grupos económi$\cos$ y sus vinculaciones externas, sino que las distintas fracciones de clase ${ }^{33}$ se encuentran estructuralmente subordinadas a la necesidad de establecer relaciones específicas, a pactar, con los grupos internos y externos, como tequisito para garantizar la continuidad del crecimiento.

$\mathrm{El}$ enfrentamiento de la segunda etapa de industrialización en varios de los países Iatinoamericanos llevó, así, a la ruptura inevitable de la base bonapartista en que se apoyaba la política que caracterizó el período anterior - el cardenismo, sobre todo, en México- y a la imposibilidad histórica de la burguesía para llevar a cabo una política de desarrollo capitalista autónomo.

A partir del momento en que la burguesía y el Estado decidieron hacer frente a las dificultades implícitas a la formación de bienes intermedios y de capital mediante la apertura del mercado interno a las subsi. diarias extranjeras y a través de una política desartollista en favor de la acumulación rápida de capitales sin intenciones redistributivas, el Estado, por su parte, redujo su carácter de Estado-empresario circunscribiendo cada vez más su actividad a aquellas iniciativas demasiado arriesgadas para el capital privado, a conservar y eventualmente ampliar su control sobre ciertos sectores fundamentales - ila energía eléctrica, por ejemplo- $y$, sobre todo, a asumir funciones reguladoras.

Por su parte, como se ha dicho, el sector nacional de la burguesía industrial, que sobre todo logró establecerse en el tipo de empresas aso. ciadas a la primera fase del proceso sustitutivo, comenz6 a depender de manera creciente de un nuevo tipo de relaciones «interempresariales» con el sector externo. La pérdida de dinamismo de las actividades productoras de bienes de consumo a partir sobre todo de la década de los 50 por el debilitamiento gradual de las posibilidades de sustitución y el lento crecimiento de la demanda dadas las características de la distribución del jn-

33. Sobre el concepto de efracción de clase», véase Nicos Poulantzas, Clases sociales y poder politico en el Estado capitalista (México: Siglo XXI, 1972) y, especialmente, Antonio Gramsci, Los intelectuales y la organizacion de la cultura; Note sul Macbiaveli, sulla politica e sullo stato moderno; y su Antologia, publicada por Siglo XXI Editores, S. A., México, 1970. 
greso, ${ }^{34}$ indujo a las élites empresariales locales a explorar en actividades más redituables pero que, a la vez, demandaban mayotes volúmenes de capital y, sobre todo, una tecno ogía más avanzada.

Es así como el nuevo tipo de relaciones interempresariales se tradujo en una pétdida de autonomía pura la burguesía nacional, que pasó a hacer depender su posibilidad de expansión del know bow obtenido directa. mente desde el exterior o bien mediante la estrategia basada en la integración de capitales nacionales y extranjeros, en la que con frecuencia la participación nacional queda supeditada al control tecrológico, financieto y administrativo de la empresa o el gtupo extranjero. ${ }^{35}$

No setía posible, sin embargo, suponer que exista una relación de oposición y conflicto entre los intereses de la burguesía nacional y los del capital extranjero, así como tampoco lo sería el imaginar un desacuerdo de la burguesía industrial con la orientación asumida por el proceso de desarrollo. Aur sin dar por discontadas las tensiones que puedar estar implicadas, Ia industrialización se ha desarrollado a través de una alianza establecida entre los sectores que detentan una cierta hegemonía y que comparten, en Io fundamental, la misma orientación: favorable a la promoción del desarrollo entendido como acumulación de capital y diversificación de la estructura productiva y la que «por lo que al control nacional o extranjero de la economía se :efere» es prácticamente neutral..$^{36}$

Por otra parte, constituirí un exceso de simplificación el pretender que la evolución de la idea de un desarrollo autónomo hacia una efectiva integración con el capitalismo transnacional fue el resultado de un voluntarismo irresponsable de las élies empresariales. El análisis estructural de la industrialización en las sociedades periféricas asume los rasgos de una internacionalización creciente de: la vida económica que no se expresa sólo en el mercado, sino también en la desnacionalización del capital, de los intereses y de la ideología y que se sintetiza en un proceso de integración transnacional - desintegración na ional. Como consecuencia, la explicación de la ideología butguesa no puedı: ser organizada a partir de una supuesta «teoría del desarrollo nacional», en la que la noción de economía se hace equivalente a la noción de paí; o nación, sino a partir del análisis espe-

34. Importantes observaciones al respecto, para el período 1950-1966, en David Ibarka, «Mercados...», op. cit., pp. 110-112. adecuada.

35. En este sentido, la nocicin de corporaciones ttansnacionales resulta más

36. F. H. Cardoso y E. Faletto, Dependencid..., op. cit., p. 158, y Osvaido Sunkel, «Capitalismo transnacional y desintegración nacional en América Latina», en Estudios Internacionales, núm. 16 (1971). 
cífico de sus situaciones de clase tal y como se conforman, articulan y expresan en un sistema nacional dependiente. En este mismo sentido, el propio concepto de «burguesía nacional» necesita ser redefinido desde el momento en que la ideología y el comportamiento político de la burguesía están regidos, más que por los intereses de la «sociedad nacional», por sus intereses internacionalizados como clase, a partir de los cuales se define el posible contenido del "problema nacional». ${ }^{37}$

Todo ello no significa, por supuesto, que no existan, dentro de la burguesía industrial, orientaciones ideológicas que tiendan a subrayar los principios del nacionalismo económico e incluso a insistir sobre la necesidad de un mayor intervencionismo estatal y una política redistributiva del ingreso. No obstante, esa ideología, sustentada principalmente por los grupos empresariales que quedaron marginados de la alianza desarrollista, - bien carecen de las condiciones estructurales mínimas para aiterar sensiblemente el nuevo esquema de dominación económica y política, o bien enfrentan limitaciones más o menos inmediatas a su vocación nacionalista en virtud, precisamente, de la cristalización de sus intereses de clase.

En términos generales, por su parte, es evidente que la estrategia politica del desarrollismo asociado busca alcanzar un cierto grado de legitimidad, vinculando a los intereses de la clase dominante a diversos grupos - fracciones de clase que se benefician de manera directa o indirecta del sector capitalista avanzado e internacionalizado y que teclutan tanto dentro de los sectores de la llamada clase media como de los sectores populares, especialmente urbanos de clase obreta, contribuyendo a fraccionalizar, verticalmente, la estructura de intereses entre los grupos y clases sociales.

No obstante, la exclusividad de la participación que es inherente a este modelo de desarrollo es insuficiente desde el punto de vista de sus tentativas de legitimación. En la práctica, el abandono de la política bonapartista y de las aspiraciones al desarrollo capitalista autónomo, condujo, en varios países, a la cafda de los regímenes liberal-democráticos que intentaron afirmarse en la situación anterior y a la implantación de dictaduras tecnocrático-militares, acentuando el papel directivo del Estado. En el caso mexicano, se mantuvo el tégimen «liberal-democrático» constitucional cuyo comportamiento simbólico contrasta con el de un autoritarismo efectivo

37. Esto plantea un importante problema teórico-metodológico entre los conceptos de Estado, Clase y Nación, así como entre Imperialismo y Dependencia. Ha sido lúcidamente analizado por Aníbal Quijano en su «Imperialismo y capitadismo de Estado», en Sociedad y politica (1973), y por F. H. Cardoso, «Imperialismo y dependencias», en su Estado y sociedad en América latina (Buenos Aires: Ediciones Nueva Visión, 1972). 
basado en la corporativización de todas las formas de organización, representación y participación políticas.

Las condiciones de creciente marginalidad económica y política han conducido, sin embargo, a una rufíficación permanente del Estado, por parte de muy diversos sectores sociales, como instrumento indispensable para la imposición de un cierto tipo de reotientaciones tendentes a la realización de un progreso más justamente compartido. ${ }^{38}$

En efecto, aún cuando el Istado, en última instancia, pueda ser ca" racterizado como la expresión del sistema social del que ha surgido y, por tanto, como la unidad esencial de articulación de los intereses de las clases o de las fracciones hegemónicas de ellas, asegurando la estructura de dominación en que se realizan las formas de apropiación, el Estado no actúa, siempre y necesariamente, bajo condiciones de subordinación absoluta a los intereses de una clase. Por $€ 1$ contratio, el mínimo de legitimación que está estructuralmente obligado a obtener en favor de un desarrollo desigual, lo lleva no sólo a dar respuesta $i$ ciertos intereses generales de la sociedad, sino, en esa misma medida, a aparecer como instancia autónoma y supraordinada a los intereses de los grupos y las clases sociales. Más aún, el Estado se presenta, bajo ciertas condiciones de tensión, como el moderador de las diferencias que en oxasiones se manifiestan entre las fracciones de la propia burguesía o de los conflictos entre ésta y las clases y grupos dominados cuando adquieren te: dencias disruptivas que amenazan la esta. bilidad del sistema social globa'. ${ }^{39}$

Así, el Estado podría estar, eventualmente, en condiciones de elaborar una política orientada a la promoción de ciertos cambios en la pauta de desarrollo capaces de traduci se, aunque dentro de los límites del tefor* mismo autoritario, en una respuesta relativamente efectiva a las demandas que presionan en favor de un desarrollo genetador de más empleos y una intención redistributiva más eficaz. Igualmente, a las que lo hacen en favor de un mayor y más efectivo control sobre las inversiones extranjeras y sus mecanismos de descapitalización nacional y, en general, a aquellas que se expresan en la idea de un desarrollo más integtado tanto económica como políticamente.

La viabilidad de estas reotientaciones pone en juego, entretanto, la propia estructura del sistema sibbre la que descansa el Estado mexicano, la alteración de las características que enmarcan la relación burguesía-

38. Al respecto consúttese el trabajo de Octavio Janni Estado e capitalismo (Río de Janeito: Editora Civilizaçăo Brasi eira, S. A., 1965), pp. 115-117.

39. Marcos Kaplan, «Estado, cependencia externa y desarrollo en América Latua*, en La crisis de desarrollismo 3 la nueva dependencia, op. cit., pp. 170-171. 
«Papers»: Revista de Sociología

Estado, la toletancia ideológica y política efectiva a los procesos de otganización autónoma de los intereses, principalmente populares, y el robustecimiento de los centros autónomos de decisión, sin todo lo cual la voluntad de transformación asume una mera verbalización ideológica. La viabilidad estructural del reformismo, como conducta política, lo impele a asumir los riesgos inherentes a la alteración de la estructura de dominación económica y política, en lo interno y en lo externo, que lo harían virtualmente probable.

\section{Ricardo CinTa}

El Colegio de México

Camino Al Ajusco, 20

México 20, DF

México 